\title{
The turkish adaptation of the QSD-R in the turkish republic of northern cyprus
}

\begin{abstract}
The purpose of this study was to examine the reliability and validity of the Questionnaire on Stress in Diabetes Patients-Revised (QSD-R) and adapt it to the Turkish language for possible clinical use with diabetic patients in the Turkish Republic of Northern Cyprus (TRNC). A forward and backward translation was done by native speakers and professionals in the field. Translation consistency was reached and a pilot study confirmed that the level of comprehension of the Turkish version of the QSD-R. The study was conducted with 500 participants, over the age of 18years of age with a confirmed diagnosis of diabetes at two state hospitals located in the TRNC. Twenty-two faulty questionnaires were removed and 478 questionnaires were examined. Multiple exploratory factor analyses using principal components analysis with varimax rotation resulted in the removal 7 items from the original questionnaire leaving a total of 38 items and yielded seven factors. Initial reliability analysis was found to be .939 ; however, after the items were removed, reliability analysis for the entire scale was found to be .843, which suggests that the QSD-R-TR is a reliable instrument. Validity for the QSD-R-TR was analyzed by conducting a discriminant validity analysis. QSD-R-TR subscale correlations were below $<.70$ which suggests that discriminant validity exists. Findings from this study suggest that the QSD-R-TR is a reliable and valid instrument that can be used in clinical practice with Turkish speaking diabetes patients in TRNC.
\end{abstract}

Keywords: diabetes distress; qsd-r; turkish adaptation; trnc
Volume 4 Issue 3 - 2015

\author{
Nalan Linda Fraim \\ Department of Psychology, Cyprus International University, \\ Turkey \\ Correspondence: Nalan Linda Fraim, Cyprus International \\ University,Turkey, Tel 90-392-67 I I I I ,Email Ifraim@ciu.edu.tr
}

Received: October II, 2015 | Published: November 30, 2015
Abbreviations: DM, diabetes mellitus; WHO, world health organization; ADA, american diabetes association; IDF, international diabetes federation; MENA, middle east north africa region; TRNC, turkish republic of northern cyprus; QSD-R, questionnaire on stress in diabetes patients revised; QSD-R-TR, questionnaire on stress in diabetes patients revised turkish; EFA, exploratory factor analysis; SPSS, statistical package for the social sciences; SD, standard deviation; KMO, kaiser-meyer olkin

\section{Introduction}

Diabetes Mellitus (DM) is a serious and possibly life threatening metabolic disorder that can result in dangerous consequences if not taken seriously. ${ }^{1}$ As like any disorder, DM requires that the person engage in continuous monitoring and evaluation, make long-term lifestyle changes, eat healthy, and live an active life. ${ }^{2}$ While making changes to life-long habits and routines can be both difficult and stressful for the person, coping with symptoms and requirements of the disease can also be stressful and create a negative perspective towards disease management. ${ }^{3-8}$

According to the World Health Organization (WHO $)^{9}$ approximately $9 \%$ of adults over the age of 18 are currently diagnosed with diabetes. In 2012, WHO reported that 1.5 million deaths occurred from diabetes and $80 \%$ of these deaths occurred in low and middle income countries. The 2014 National Diabetes Statistics Report reported that in 2012, 9.3\% of the American population had diabetes and that 8.1million were undiagnosed. According to American Diabetes Association ADA, the prevalence rate of diabetes in seniors ages 65 or older is $25.9 \%{ }^{1}{ }^{1}$ While diabetes was the 7 th leading cause of death in the United States in 2010, 69.071 deaths were caused directly by diabetes. ${ }^{1}$ The International Diabetes Federation (IDF) reported that while the current prevalence is $8.3 \%$ of the world population, currently 387 million people are living with diabetes and by 2035 , this number is expected to reach approximately 400 million. ${ }^{10}$ As per the IDF diabetes atlas, the prevalence rate in Europe is $7.9 \%$ and the Middle East and North Africa (MENA) Region is 9.7\%. ${ }^{10}$

The island of Cyprus is situated in the eastern Mediterranean and is located in the MENA region. According to the Turkish Republic of Northern Cyprus (TRNC) Diabetes Association 11\% of the population was diagnosed with Type 1 or Type 2 diabetes and $18 \%$ of the population was considered to be pre-diabetic. ${ }^{11}$ In the last population census done in 2011, the TRNC population was reported to be 295,000 . When considering the overall diabetic and pre-diabetic prevalence rates in the TRNC, it can be estimated that approximately 86,000 people are currently living with diabetes. No other statistical information on prevalence, incidence, mortality or morbidity is available in the TRNC. ${ }^{11}$

There are a variety of scales that are currently used worldwide to measure various diabetes related issues and symptomology; ${ }^{12-22}$ however, in Turkey and the TRNC, there is a huge gap in this area. While this gap affects clinical practice and creates a barrier for future research, stress related symptomology experienced by diabetic patients are great ignored and this situation has a negative impact on the treatment quality provided, the patient's treatment adherence, and the patient's overall quality of life. According to the Turkish Higher Education Institute's Thesis/Dissertation database, currently there are a total of 1278 diabetes related theses (master's and $\mathrm{PhD}$ combined); however, only 3 related to diabetes inventories were found: the Diabetes Fear of Self Injecting \& Self-Testing Questionnaire in 2010; the Problem Ares in Diabetes in 2011; the Diabetes Empowerment Scale in 2012. The Problem Areas in Diabetes which was originally translated by a medical student earlier; however, never standardized. ${ }^{23}$

\section{Purpose of the Study}

When it comes to assessing stress related to diabetes, there are no 
instruments in Turkish that specifically address patient experienced stresses related to diabetes. This creates a great problem for treatment, research, program development, and diabetic stress specific program implementation. The purpose of this study was to adapt the QSD-R to Turkish and examine its appropriateness for clinical use in the TRNC.

\section{Materials and methods}

\section{Participants}

A total of 500 randomly selected participants, ages 18 and older and with a confirmed diagnosis of either Type I, Type 2, or Gestational diabetes from the endocrinology clinic at either Girne Dr. Akçiçek State Hospital, located in the city of Kyrenia, and Dr. Burhan Nalbantoglu State Hospital, located in Nicosia in the Turkish Republic of Northern Cyprus (TRNC) were included in this study After obtaining written consent from the participants to participate in the study, participants were given a protocol number to maintain anonymity and the researcher gave the questionnaire to the participant to complete. For participants without reading and writing skills, the researcher read the statements to the participant and marked the participant's answer accordingly. All questionnaires were kept confidential. After all surveys were completed, a preliminary analysis was conducted and a total of 28 surveys were removed from the data set due to incompletely filled out surveys. The final sample size for this study was 478 . Data for this study was collected between June 2014 and March 2015. Written permission to conduct research at these hospitals was obtained from the TRNC Ministry of Health.

\section{Instrument}

Two instruments were given to the participants in the survey package:

\section{A Demographics Information Form and}

\section{The Turkish version of the QSD-R.}

The Demographics Information Form is a basic information form containing five questions pertaining to the participant's age, gender, diabetes diagnosis, when they were diagnosed, and whether or not they have a family history of diabetes. The English version of the QSD- ${ }^{24}$ is a self-administered instrument developed to measure stresses related to diabetes and contains 45 questions that define eight stress subscales for patients with diabetes: leisure time, depression/ fear of future, hypoglycemia, treatment regimen/diet, physical complaints, work, partner, and doctor-patient relationship. The numbers of items for each subscale is defined as follows: 2, 9, 18, 30 in leisure time; 28, 34, 40, 42, 43, 45 in depression/fear of future; 12 , $22,25,31$ in hypoglycemia; $1,5,8,10,13,21,26,37,39$ in selfmedication/diet; $6,17,19,20,38,44$ in physical complaints; 4,11 , $16,27,33,41$ in work; 3, 14, 15, 24, 35, 36 in partner; and 7, 23, 29, 32 in doctor-patient relationship. Each item has a 5-point Likert scale ranging from " 1 " (only a slight problem) to " 5 " (very big problem). For each statement, participants are asked to mark an " $\mathrm{X}$ " to which conditions applies to them. In addition, for statements that are not relevant to the participant, an additional option of "Does not apply to me" was present. If the statement did not apply to the participant, participants were asked to mark an "X" in this option. Cronbach's alpha for the subscales were reported as $.81, .80, .75, .71, .75, .70$, .69 , and .69 , respectively. In addition, test-retest reliability scores for the subscales were found to be $.58, .58, .64, .45, .68, .73, .59$, and .62 respectively and the total test-retest reliability was found to be .63 after a 5-week interval. ${ }^{24}$

\section{Procedure}

The linguistic adaptation is of the QSD-R from English to Turkish was done via a double forward and backward translation. Native speakers and experts in the field were consulted for this. Translated versions were compared for linguistic consistency. A pilot study of 10 participants was conducted to examine the level of comprehensibility. Participants were randomly selected from people walking around in the hospital lobby, sitting in the cafeteria, or waiting outside in the hospital garden. Participants were asked if they would like to participate in a 10-15minute brief experiment where the level of comprehension of a survey instrument was being examined. Participants were told that they did not have to answer any of the statements in the survey but rather look at the wording, meaning, and overall comprehension of the inventory.Participants who agreed to participate were given the survey and asked to read through the directions and then the statements. The researcher did not interrupt the participant during this process. When participants were done reading the survey, the researcher asked the participants three questions:

1. Is the wording of the directions and the statements clear?

2. Are the statements understandable?

3. Did you have any difficulties in reading or understanding the survey?

No demographic information from the participants was recorded. Results suggest that the directions and statements on the questionnaire were clear and understandable.

\section{Data analysis}

The QSD-R contains 45 items. To conduct a factor analysis, per item a minimum of 10 questionnaires per item are required; ${ }^{25}$ therefore, a total of 450 questionnaires were needed for this study. However, taking into consideration that there could be faulty questionnaires, questionnaires filled out reflecting the social desirability bias, and possible misunderstandings, the researcher collected a total of 500 questionnaires in total. As mentioned earlier, due to faulty and incomplete questionnaires, 22 questionnaires were removed and the final number of questionnaires for this study was $n=478$. Data was analyzed using SPSS v.21.An exploratory factor analysis (EFA) was used to test the construct validity of the QSD-R-TR. To test the reliability of the instrument, item-total correlations Cronbach alpha internal consistency coefficients were examined.

\section{Results and discussion}

\section{Demographic information}

A total of 478 participants randomly participated in this study; 49.6 $\%$ males and $53.1 \%$ females. Ages of the participants ranged from 18 to 97 and the mean age was $50.39(\mathrm{SD}=14.53)$. In terms of diagnosis type, $43.9 \%$ of the sample was diagnosed with Type 1 diabetes and $49.8 \%$ with Type 2 diabetes. A majority of the sample $64.2 \%$ had a family history of diabetes. When looking at when the participants were diagnosed with diabetes, regardless of type, a large majority of the sample (64.6\%) was diagnosed after the year 2000. Demographic data analysis can be found in Table 1 .

\section{Reliability analysis}

Reliability analysis for the translated version of the QSD-R was examined using Cronbach's alpha internal consistency coefficient for the instrument and was found to be .939 for 45 items. However, 
items $5,12,21,23$, and 40 were excluded from the scale due to their corrected item-total score correlations being below .30 (-.038, .161, $.085, .269$, and .078 , respectively). Correlation values less than .30 suggests that these items do not measure the same construction as well other items. ${ }^{26}$ After these items were excluded, the re-tested Cronbach's alpha was found to be .946 for 40 items, which suggests that the QSD-R-TR is reliable. The final item-total correlations ranged from .301 (item 4) to .736 (item 14). The Corrected Item-Total Correlations and Cronbach's Alpha for the If Item Deleted values are reported in Table 2.

Table I Demographics distribution table

\begin{tabular}{|c|c|c|}
\hline & $\mathbf{n}$ & $\%$ \\
\hline \multicolumn{3}{|l|}{ Gender } \\
\hline Male & 224 & 46.9 \\
\hline Female & 254 & 53.1 \\
\hline \multicolumn{3}{|c|}{ Age Groups } \\
\hline $18-27$ & 26 & 5.4 \\
\hline $28-37$ & 75 & 15.7 \\
\hline $38-47$ & 92 & 19.2 \\
\hline $48-57$ & 127 & 26.6 \\
\hline $58-67$ & 98 & 20.5 \\
\hline $68-77$ & 48 & 10.2 \\
\hline $78-87$ & II & 2.3 \\
\hline$>88$ & I & 0.2 \\
\hline \multicolumn{3}{|c|}{ Diabetes Diagnosis } \\
\hline Type I & 210 & 43.9 \\
\hline Type 2 & 238 & 49.8 \\
\hline Gestational & 28 & 5.9 \\
\hline Other & 2 & 0.4 \\
\hline \multicolumn{3}{|c|}{ Family History } \\
\hline Yes & 307 & 64.2 \\
\hline No & 191 & 35.8 \\
\hline \multicolumn{3}{|c|}{ Diagnosis Date } \\
\hline $196 \mid-1970$ & 4 & 0.8 \\
\hline$|97|-1980$ & 20 & 4.2 \\
\hline$|98|-1990$ & 61 & 12.8 \\
\hline$|99|-2000$ & 79 & 16.5 \\
\hline $200 I-2010$ & 177 & 37 \\
\hline After 20ll & 132 & 27.6 \\
\hline
\end{tabular}

\section{Validity analysis}

To measure the construct validity of the QSD-R-TR, an EFA using Principal Component Analysis was performed using Varimax rotation to identify the factors of the 40 items for validity. In order to establish unsuitable variables for factor analysis, tests that measure appropriate sampling size such as Kaiser-Meyer-Olkin (KMO) sampling adequacy and Bartlett's test of sphericity were applied $(\mathrm{KMO}=.937 ; \mathrm{p}=.000)$. These findings implied that the sampling size that was used in the study was large enough to perform the factor analysis and that the data was normally distributed. ${ }^{27}$ Communalities were examined and all communalities were above $.40(\min =.466$ item 45 and $\max =.747$ item 36). Eigen values are used as the decision making criterion to decide on how many factors should be retained in the analysis and Eigen values higher than 1.00 are considered to be significant. ${ }^{25}$ The first analysis yielded seven factors explaining $62.11 \%$ of the total variance; however, only one item was found in Factor 7 (item 38). For a factor to be considered as a valid "factor", a minimum of two items are required. Based on this principle, this item was removed and the analysis was redone. The second analysis yielded a total of 7 factors explaining $62.64 \%$ of the total variance; however, no factor loading was reported for item 39, which was removed and the analysis was repeated. Results from the third analysis yielded a total of 7 factors which explained $63.08 \%$ of the total variance. A total of 38 items remained on the QSD-R-TR. Factor loadings for 38 items of the QSD$\mathrm{R}-\mathrm{TR}$ are reported in Table 3.

Factor 1 consists of eleven items (item 6, 14, 16, 17, 18, 19, 20, $25,31,42$, and 44 ) related to impaired effect of diabetes on psychophysiological functions and was labeled as "psycho-physiological aspects." Factor 2 consists of six items (item 4, 15, 24, 26, 27, and 33) related to the impaired social effects of diabetes on the patient and was labeled as "social". Factor 3 includes six items (item 1, 2, 9, 10, 11, and 13) related to the patient's responsibilities regarding the disease and was labeled as "accountability". Factor 4 consisted of four items (item $35,36,37$, and 41) which were related to the negative effects in the psychosocial dimension such as relationship with partner, or work. This factor was labeled as "psychosocial distress".Factor 5 consisted of four items (item 3, 8, 43, and 45), which represents fear of the future, depression, self-medication, and partner and was labeled as "fear/ depression". Factor 6 consisted of three items (item 22, 28, and 34) which represents outcomes related to the disease and this factor was labeled as "outcomes". Factor 7 consisted of four items (item 7, 29, 30 , and 32), which represents the relationship quality between doctor and patient and this factor was labeled as "medical relationship". The internal consistency for each of the scales was examined using Cronbach's alpha. Correlation values for the seven factors suggests that the subscales were reliable $(.825, .636, .780, .804, .771, .666$, and .633 , respectively). Total scale reliability, after all items were removed and grouped accordingly was found to be .834 , which suggests that the Turkish version of the QSD-R is a reliable scale.

Discriminant validity is tested to ensure that the subscales are related by analyzing the correlations between them. ${ }^{28}$ When the correlations between the scales are lower than $<.70$ this suggests that the scales theoretically assess different concepts and has Discriminant validation..$^{29}$ In the original QSD-R study, subscales were reported to be appropriate by comparing distress levels on patients regarding different diabetes criteria such as diabetes type, diabetes duration, HbA1 level, and treatment setting in the Discriminant validity analysis ${ }^{24}$ however, the researchers did not analyze the correlations between the original QSD-R scale and its subscales for Discriminant validity. Scale and subscale correlations for the QSD-R-TR were examined using Pearson Product Moment Correlation analysis. Results suggest that the scale has Discriminant validity (Table 4). 
Table 2 Primers for RT-PCR

\begin{tabular}{|c|c|c|c|}
\hline No. & Items & $\begin{array}{l}\text { Corrected Item- } \\
\text { Total Correlations }\end{array}$ & $\begin{array}{l}\text { Cronbach's Alpha if } \\
\text { Item Deleted }\end{array}$ \\
\hline I & My diabetes makes me give up tasty foods & 0.43 & 0.945 \\
\hline 2 & I have to plan my free time because of my diabetes. & 0.472 & 0.945 \\
\hline 3 & I am worried about my spouse / partner. & 0.574 & 0.945 \\
\hline 4 & $\begin{array}{l}\text { Promotional prospects in my current job are limited because of my } \\
\text { diabetes. }\end{array}$ & 0.301 & 0.946 \\
\hline 6 & I suffer from "wind". & 0.313 & 0.946 \\
\hline 7 & Different doctors give me different information regarding my diabetes. & 0.31 & 0.946 \\
\hline 8 & At times I can't help worrying that I will develop complication later in life. & 0.636 & 0.944 \\
\hline 9 & $\begin{array}{l}\text { It bothers me that, whatever I do, I have to take my therapeutic } \\
\text { equipment with me. }\end{array}$ & 0.643 & 0.944 \\
\hline 10 & Often there is not enough food in my diet plan to feel full. & 0.421 & 0.946 \\
\hline II & $\begin{array}{l}\text { The idea of being alone at work or at home for long episodes of time } \\
\text { frightens me. }\end{array}$ & 0.571 & 0.945 \\
\hline 13 & $\begin{array}{l}\text { Having diabetes means I must eat even if I am not hungry or not having } \\
\text { appetite. }\end{array}$ & 0.46 & 0.945 \\
\hline 14 & My physical ability is limited because of my diabetes. & 0.724 & 0.943 \\
\hline 15 & I feel less attractive to others since I developed diabetes. & 0.532 & 0.945 \\
\hline 16 & My diabetes prevents me from spontaneous physical activities. & 0.736 & 0.943 \\
\hline 17 & I suffer from excessive sweating. & 0.561 & 0.945 \\
\hline 18 & Traveling has become complicated and awkward because of my diabetes. & 0.625 & 0.944 \\
\hline 19 & I suffer from episodes of weakness / lack of energy. & 0.644 & 0.944 \\
\hline 20 & I often suffer from physical distress or discomfort due to my diabetes. & 0.642 & 0.944 \\
\hline 22 & $\begin{array}{l}\text { During low blood sugar I suffer from emotional states one might describe } \\
\text { as "irritable, aggressive". }\end{array}$ & 0.515 & 0.945 \\
\hline 24 & I have had less sex since the onset of my diabetes. & 0.465 & 0.945 \\
\hline 25 & I often worry about passing out during low blood sugars. & 0.537 & 0.945 \\
\hline 26 & $\begin{array}{l}\text { It sometimes happens that friends try to talk me into "not following my } \\
\text { treatment plan just this once". }\end{array}$ & 0.478 & 0.945 \\
\hline 27 & Having diabetes makes it particularly hard for me to find a new job. & 0.386 & 0.946 \\
\hline 28 & I suffer from irritability. & 0.521 & 0.945 \\
\hline 29 & My doctors do not spend enough time with me & 0.499 & 0.945 \\
\hline 30 & Due to my diabetes, I cannot spend free time as I wish. & 0.636 & 0.944 \\
\hline 31 & $\begin{array}{l}\text { My activities at home and / or at work are made more difficult at times } \\
\text { because of my diabetes. }\end{array}$ & 0.639 & 0.944 \\
\hline 32 & $\begin{array}{l}\text { I have the impression that my doctor does not treat my diabetes in the } \\
\text { best possible way. }\end{array}$ & 0.412 & 0.946 \\
\hline 33 & I have problems at work due to sick days caused by my diabetes. & 0.46 & 0.945 \\
\hline 34 & I suffer from intense mood swings. & 0.519 & 0.945 \\
\hline 35 & $\begin{array}{l}\text { My relationship with my spouse / partner has become worse of my } \\
\text { diabetes. }\end{array}$ & 0.613 & 0.944 \\
\hline 36 & I feel like a handicapped person. & 0.654 & 0.944 \\
\hline 37 & $\begin{array}{l}\text { It is difficult for me to have mentioned my diet on parties or in } \\
\text { restaurants. }\end{array}$ & 0.662 & 0.944 \\
\hline 38 & I suffer from pain in my feet. & 0.384 & 0.946 \\
\hline 39 & Pricking my finger to monitor my blood sugar is uncomfortable. & 0.605 & 0.944 \\
\hline 41 & In some ways I feel I am at a disadvantage compared to other people. & 0.681 & 0.944 \\
\hline 42 & I suffer from nervousness / restlessness. & 0.648 & 0.944 \\
\hline 43 & I often worry about needing assistance later in life. & 0.688 & 0.944 \\
\hline 44 & I am often thirsty or have a dry mouth. & 0.55 & 0.945 \\
\hline 45 & At times I worry that my children may also get diabetes. & 0.307 & 0.946 \\
\hline
\end{tabular}

Table 3 Factor loadings with percentage of total variance explained

\begin{tabular}{|c|c|c|c|c|c|c|c|}
\hline Questionnaire Items & Factor I & Factor 2 & Factor 3 & Factor 4 & Factor 5 & Factor 6 & Factor 7 \\
\hline Item I & & & 0.678 & & & & \\
\hline Item 2 & & & 0.726 & & & & \\
\hline Item 3 & & & & & 0.478 & & \\
\hline Item 4 & & 0.771 & & & & & \\
\hline Item 6 & 0.529 & & & & & & \\
\hline
\end{tabular}


Table Continued..

\begin{tabular}{|c|c|c|c|c|c|c|c|}
\hline Questionnaire Items & Factor I & Factor 2 & Factor 3 & Factor 4 & Factor 5 & Factor 6 & Factor 7 \\
\hline Item 7 & & & & & & & 0.653 \\
\hline Item 8 & & & & & 0.54 & & \\
\hline Item 9 & & & 0.525 & & & & \\
\hline Item 10 & & & 0.729 & & & & \\
\hline Item II & & & 0.442 & & & & \\
\hline Item I3 & & & 0.453 & & & & \\
\hline Item I4 & 0.617 & & & & & & \\
\hline Item I5 & & 0.462 & & & & & \\
\hline Item 16 & 0.605 & & & & & & \\
\hline Item 17 & 0.614 & & & & & & \\
\hline Item 18 & 0.802 & & & & & & \\
\hline Item 19 & 0.725 & & & & & & \\
\hline Item 20 & 0.672 & & & & & & \\
\hline Item 22 & & & & & & 0.75 & \\
\hline Item 24 & & 0.555 & & & & & \\
\hline Item 25 & 0.76 & & & & & & \\
\hline Item 26 & & 0.583 & & & & & \\
\hline Item 27 & & 0.82 & & & & & \\
\hline Item 28 & & & & & & 0.69 & \\
\hline Item 29 & & & & & & & 0.567 \\
\hline Item 30 & & & & & & & 0.475 \\
\hline |tem 3| & 0.569 & & & & & & \\
\hline Item 32 & & & & & & & 0.645 \\
\hline Item 33 & & 0.746 & & & & & \\
\hline Item 34 & & & & & & 0.508 & \\
\hline Item 35 & & & & 0.685 & & & \\
\hline Item 36 & & & & 0.749 & & & \\
\hline Item 37 & & & & 0.719 & & & \\
\hline Item 4I & & & & 0.576 & & & \\
\hline Item 42 & 0.492 & & & & & & \\
\hline Item 43 & & & & & 0.541 & & \\
\hline Item 44 & 0.54 & & & & & & \\
\hline Item 45 & & & & & 0.626 & & \\
\hline$\%$ of Total Variance Explained & 33.827 & 10.502 & 5.93 & 4.011 & 3.199 & 2.878 & 2.736 \\
\hline Cumulative $\%$ & 33.827 & 44.33 & 50.259 & 54.27 & 57.47 & 60.348 & 63.084 \\
\hline Number of test measures & II & 6 & 6 & 4 & 4 & 3 & 4 \\
\hline
\end{tabular}

Note: Factor loadings $<.30$ are suppressed

Table 4 Pearson's correlations between the QSD-R scale and subscales

\begin{tabular}{|c|c|c|c|c|c|c|c|c|}
\hline & Factor I & Factor 2 & Factor 3 & Factor 4 & Factor 5 & Factor 6 & Factor 7 & Total Scale \\
\hline Factor I & ------- & & & & & & & \\
\hline Factor 2 & $.390 * *$ & ------- & & & & & & \\
\hline Factor 3 & $.596 * *$ & $.295 * *$ & ------- & & & & & \\
\hline Factor 4 & $.639 * *$ & $.544 * *$ & $.544 * *$ & ------- & & & & \\
\hline Factor 5 & $.656 * *$ & $.333 * *$ & $.689 * *$ & $.573^{* *}$ & ------- & & & \\
\hline Factor 6 & $.530 * *$ & $.316 * *$ & $.54 \mathrm{I} * *$ & $.462 * *$ & $.518 * *$ & ------- & & \\
\hline Factor 7 & $.377^{* *}$ & $.689 * *$ & $.341 * *$ & $.544 * *$ & $.279 * *$ & $.283^{* *}$ & ------- & \\
\hline Total Scale & $.852 * *$ & $.635^{* *}$ & $.780 * *$ & $.804 * *$ & $.77 I^{* *}$ & $.666 * *$ & $.633 * *$ & ------- \\
\hline
\end{tabular}

**. Correlation significant at $\mathrm{p}=0.0 \mathrm{I}$.

\section{Conclusion}

Assessing the psychosocial aspects of any chronic disease is of great importance as many aspects are ignored by health care personnel. Today, instead of linear assessments, multi-focal assessments are required to better understand the psychological and social aspects of illness development, adaptation to the changes caused by the illness, and factors involved in adherence to the medical regimen. However, in order to conduct these assessments, instruments need to be made available. In the English speaking world, this is not a problem because there are a plethora of inventories developed and used; however, in developing countries like the TRNC where Turkish is the primary spoken language, such instruments are not available for clinical practice or research. The lack of such instruments contributes to the abovementioned psycho-social aspects of chronic illness to be ignored. This study examined the Turkish adaptation of the QSD-R in the Turkish Republic of Northern Cyprus. Although the Turkish version is shorter than the original English version, the results from this study 
suggest that the QSD-R-TR is a reliable and valid instrument that can be used with Turkish speaking diabetic populations for clinical and research purposes.

\section{Acknowledgements}

The author would like to thank Busra Dumanlı, Sibel Uyanır, and Selcin Zekai for their help in data collection. Also many thanks to Prof. Dr. Osman Tolga Aricak and Prof. Dr. Nuket Sivri for their suggestions and guidance in preparing this manuscript.

\section{Conflicts of interest}

Author declares there are no conflicts of interest.

\section{Funding}

None.

\section{References}

1. Statistics about diabetes. National diabetes statistics report. American Diabetes Association. 2014.

2. Elder NC, Muench J. Diabetes care as public health. J Fam Pract. 2000;49(6):513-514.

3. Hong YY, Lim YY, Audrey LSY, et al. Providing diabetes patients with personalized written clinical information in the diabetes outpatien clinic: A pilot study. Diabetic Med. 2010;27(6):685-690.

4. Lustman PJ, Clouse RE. Depression in diabetic patients: The relationship between mood and glycemic control. J Diabetes Complications. 2005;19(2):113-122.

5. Peyrot M, Rubin RR, Lauritzen T, et al. Psychosocial problems and barriers to improved diabetes management: results of the Cross-National Diabetes Attitudes, Wishes and Needs (DAWN) Study. Diabetic Med. 2005;22(10):1379-1385.

6. Richardson LK, Egede LE, Mueller M, et al. Longitudinal effects of depression on glycemic control in veterans with Type 2 diabetes. Gen Hosp Psychiatry. 2008;30(6):509-514.

7. Rubin RR, Peyrot M. Quality of life and diabetes. Diabetes Metab Res Rev. 1999;15(3):205-218.

8. Wardian J, Sun F. Factors associated with diabetes-related distress: Implications for diabetes self-management. Soc Work Health Care. 2014;53(4):364-381.

9. Diabetes. Fact sheet no:312. World Health Organization. 2015.

10. IDF diabetes atlas. (6th edn), International Diabetes Foundation. 2014.

11. Turkish Republic of Northern Cyprus Diabetes Association. Diabetes workshop in North Cyprus. 2011.

12. Anderson RM, Funnell MM, Fitzgerald JT, et al. The Diabetes Empowerment Scale: a measure of psychosocial self-efficacy. Diabetes Care. 2000;26(6):739-743.
13. Bott U, Mühlhauser I, Overmann H, et al. Validation of a DiabetesSpecific Quality of Life Scale for patients with type 1 diabetes. Diabetes Care. 1998;21(5):757-769.

14. Bradley C, Todd C, Gorton T, et al. The development of an individualized questionnaire measure of perceived impact of diabetes on quality life: the ADDQoL. Qual Life Res. 1999;8(1-2):79-91.

15. Carey MP, Jorgensen RS, Weinstock RS, et al. Reliability and validity of the appraisal of diabetes scale. J Behav Med. 1991;14(1):43-51.

16. Dunn SM, Smartt HH, Beeney LJ, et al. Measurement of emotional adjustment in diabetic patients: Validity and reliability of ATT39. Diabetes Care. 1986;9(5):480-489.

17. Fisher L, Glasgow RE, Mullan JT, et al. Development of a brief diabetes distress screening instrument. Ann Fam Med. 2008;6(3):246-252.

18. Grootenhuis PA, Snoek FJ, Heine RJ, et al. Development of a type 2 diabetes symptom checklist: a measure of symptom severity Diabet Med. 1994;11(3):253-261.

19. Jacobson AM, de Groot M, Samson JA. The evaluation of two measures of quality of life in patients with Type I and Type II diabetes. Diabetes Care. 1994;17(4):267-274.

20. Polonsky WH, Anderson BJ, Lohrer PA, et al. Assessment of diabetesrelated distress. Diabetes Care. 1995;18(6):754-760.

21. Shen W, Kotsanos JG, Huster WJ, et al. Development and validation of the Diabetes Quality of Life Clinical Trial Questionnaire. Med Care. 1999; 37(4 Suppl Lilly):AS45-AS66.

22. Snoek FJ, Mollema ED, Heine RJ, et al. Development and validation of the diabetes fear of injecting and self-testing questionnaire (D-FISQ): first findings. Diabet Med. 1997;14(10):871-876.

23. Higher Education Association of Turkey. National Thesis Center. 2015.

24. Herschbach P, Duran G, Waadt S, et al. Psychometric properties of the Questionnaire on Stress in Patients with Diabetes - Revised (QSD-R). Health Psychol. 1997;16(2):171-174.

25. Tabachnick BG, Fidell LS. Using Multivariate Statistics. (4th edn), In: Allyn \& Bacon (Eds.), Needham Heights, USA. 2001.

26. Williams B, Brown T, Onsman A. Exploratory factor analysis: A fivestep guide for novices. Australas J Paramed. 2010;8(3):1-13.

27. Pett MA, Lackey NR, Sullivan JJ. Making sense of factor analysis: The use of factor analysis for instrument development in health research. Sage Publications. 2003.

28. John OP, Benet-Martinez V. Measurement: Reliability, construct validation, and scale construction. In: Reis HT \& Judd CM (Eds.), Handbook of Research Methods in Social and Personality Psychology. Cambridge University Press, New York, USA. 2000. p.339-369.

29. Cambell DT, Fiske DW. Convergent and discriminant validation by the multitrait-multimethod matrix. Psychol Bull. 1959;56(2):81-105. 